\title{
A Prospective Study of Total Laryngectomy and associated Complications
}

\author{
Sudarshan L Reddy, Sridhar D Reddy, AVVSL Prasad
}

\begin{abstract}
A prospective study conducted over a period of 2 years at a tertiary care hospital on all patients who underwent total laryngectomy to study the complications of the surgeries, their possible etiology. Laryngectomy is one of the most frequently done oncological surgeries in this part of the world, with high incidence of morbidity. Through improved techniques and preand postoperative protocols the incidence of complications have reduced, none the less they occur. Aim of the present study is to note the incidence of complications and their management in our setup.
\end{abstract}

Keywords: Carcinoma larynx, Laryngectomy, Complications.

How to cite this article: $R$ eddy $S L$, R eddy SD, Prasad AVVSL. A Prospective Study of Total Laryngectomy and associated Complications. Int J Phonosurg Laryngol 2012;2(1):20-22.

Source of support $\mathrm{Nil}$

Conflict of interest: None

\section{INTRODUCTION}

The study has been performed with the main objective as to study the complications of laryngectomy, identify the possible causes and their management.

\section{MATERIALS AND METHODS}

This is a prospective study conducted over a period of 2 years (A pril 2006 to M arch 2008) at Government ENT Hospital, Koti, Hyderabad. A total number of 30 male patients with an age range between 23 and 70 years, who were subjected to total laryngectomy and who subsequently developed complications were included in the study. O ut of which 23 patients underwent total laryngectomy alone, and five patients total laryngectomy and neck dissection, and two patients underwent combined procedure of total laryngectomy, partial pharyngectomy and reconstruction with pectoral is major myocutaneous flap. A total of $93.35 \%$ of the patients had a history of addiction to tobacco and alcohol. Four patients had preoperative radiotherapy. Of the 30 patients, 28 were of squamous cell carcinoma, out of which 15 were well differentiated, 11 moderately differentiated, two poorly differentiated, one each of spindle cell carcinoma and invasive keratinizing squamous cell carcinoma. Twenty-five patients were of $\mathrm{T}_{3} \mathrm{~N}_{0} \mathrm{M}_{0}$ stage, 3 were of $\mathrm{T}_{3} \mathrm{~N}_{2 \mathrm{a}} \mathrm{M}_{0}$, and one each belonged to $\mathrm{T}_{3} \mathrm{~N}_{2 c} \mathrm{M}_{0}$ and $\mathrm{T}_{4} \mathrm{~N}_{2 \mathrm{a}} \mathrm{M}_{0}$ stage. A ll the 30 patients presented with hoarseness of voice, in addition 26 of them had stridor, five of them had neck nodes and five had dysphagia. A thorough preoperative evaluation and standard treatment protocol was followed in all cases. How ever, one 70-year-old patient with prior medical condition of hypertension with left ventricular failure died due to acute myocardial infarction on first postoperative day.

\section{RESULTS}

Wound infection and dehiscence was found in 7 cases (23\%), pharyngocutaneous fistulae again in 7 cases $(23 \%)$. This was followed by recurrence of disease in 4 cases (13\%). Hematoma, pharyngocutaneous fistula due to postoperative radiotherapy, pharyngeal stenosis and stomal stenosis in 2 patients each (6.6\%). One case of abscess (3.3\%) was noted. There was one death (Fig. 1).

Wound infection and pharyngocutaneous fistula were the two most frequent complications encountered in our study (Figs 2 and 3). Increased incidence of wound infection and pharyngocutaneous fistula were observed in patients with anemia and those who were subjected to preoperative radiotherapy. Three specimens for culture and sensitivity from the infected wounds revealed pseudomonas species and were found sensitive to aminoglycosides who were successfully treated with appropriate antibiotics.

Pharyngocutaneous fistulae were probably due to anemia, preoperative radiotherapy and partial pharyngectomy and wound infection. A Il the fistulae were managed conservatively with ryle's tube feeding, high protein diet, daily wound care, multivitamin and glycopyrrolate injections. Spontaneous closure of fistulae occured between

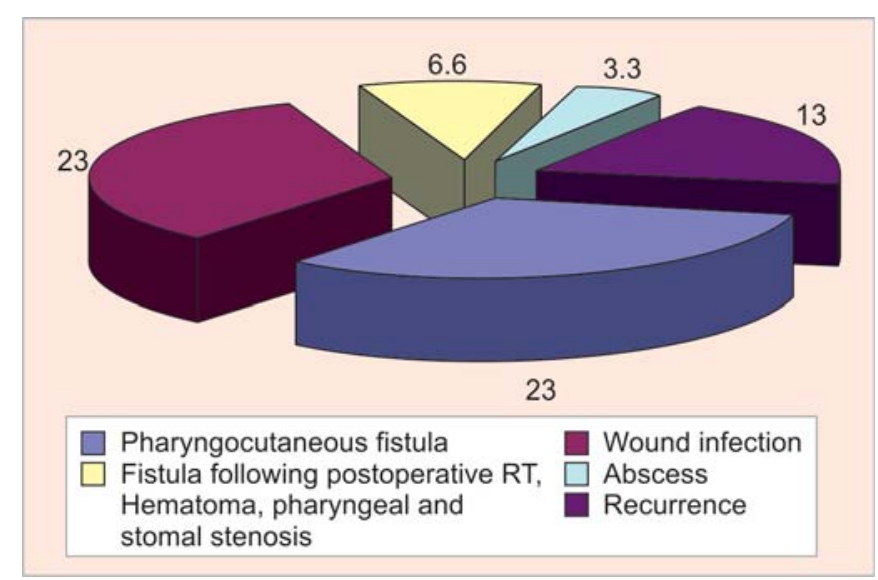

Fig. 1: The complications of laryngectomy 


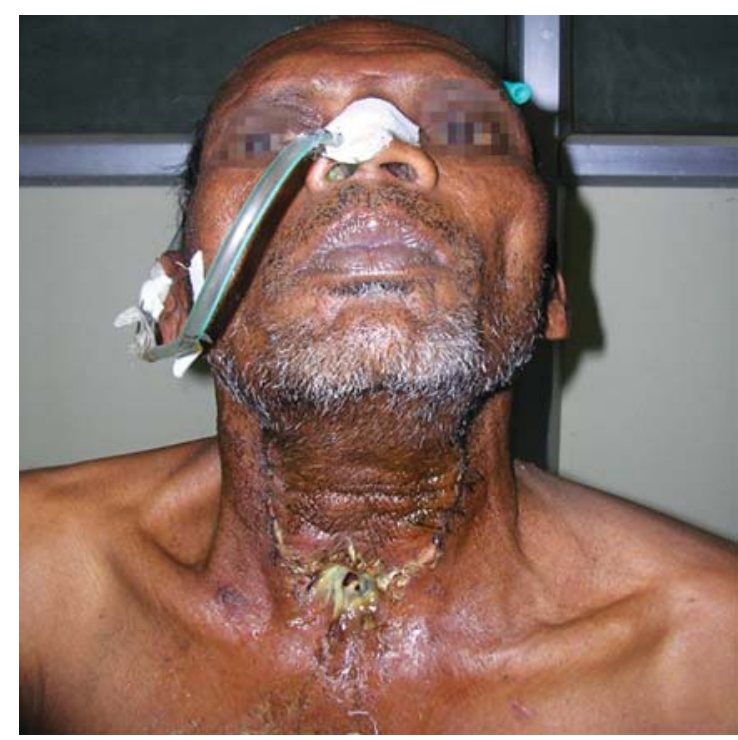

Fig. 2: Wound infection

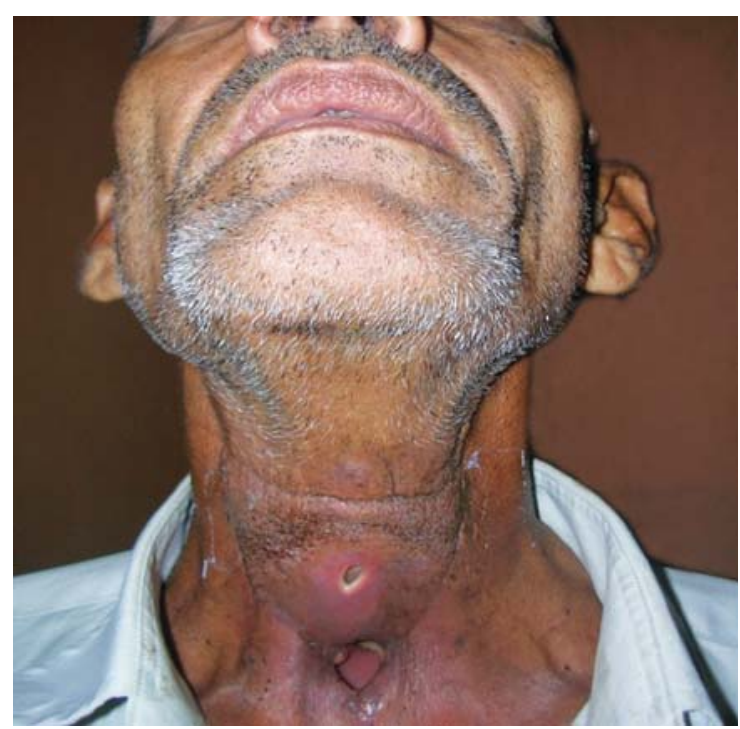

Fig. 3: P haryngocutaneous fistula

26th to 50th postoperative day with an average duration of 32 days.

Hematoma due to drain block was seen in two patients. One developed abscess after 3 weeks which was treated by $I$ and $D$ and daily dressings. Stomal stenosis occurred in two patients which were managed by dilatation and tracheostomy tube insertion. Probable reasons were stomal infection, early removal of tracheostomy tube.

Recurrence was noted in four patients of which two had nodal metastasis; one stomal recurrence and the other had skin flap metastasis. All these patients were sent for radiotherapy.

Two patients had pharyngeal stenosis probably due to excessive removal of hypopharyngeal mucosa during surgery. These patients were treated by repeated dilatations. Two patients could get good esophageal speech and one patient was kept on Blom singer prosthesis. Reasons for other patients not being rehabilitated were old age, lack of motivation, depression following surgery, lack of family support and poverty.

\section{DISCUSSION}

Billroth of V ienna, on December 31, 1873, carried out the first total laryngectomy for laryngeal cancer. Radiation therapy was very popular for laryngeal cancer during the first half of twentieth century. How ever, with improvements in surgical and anesthetic techniques and recognition of radiation therapy's limitations, surgery (including total laryngectomy) continues to play a major contemporary role. Laryngectomy, a procedure which had many complications in the initial days, has less complications with the growing expertise among otorhinolaryngologists and head and neck surgeons worldwide; we have encountered some complications in the postoperative period and were successful in managing many of them. In our series, wound infection and pharyngocutaneous fistula continue to be major complications of total laryngectomy as has been observed in various studies. ${ }^{8}$ Poor general condition, anemia, preoperative radiotherapy were temporally associated with the above complications. This suggests that preoperative improvement in general condition and planned surgery improves the outcome. Seth $\mathrm{R}$ et al concluded that preoperative radiation, prolonged operative time, low albumin and diabetes were independently associated with postoperative wound infections. ${ }^{7,9}$ These results will help to identify patients at risk for wound complications, thus allowing for heightened surveillance and preventive measures where possible. Similarly, A rriaga et al observed that the medical complications are a significant cause of morbidity in total laryngectomy; a focused preanesthetic risk factor analysis by a medical team familiar with head and neck cancer patients assures prompt identification and management of these complications. ${ }^{2}$ In our study also, we had one incident of postoperative myocardial infarction, this stresses the need to thoroughly evaluate preoperatively the patient's medical condition to avoid complications of the surgery.

Ganly et al in their study proved that primary CT RT was an independent predictor of local wound complications and pharyngocutaneous fistula. ${ }^{3,5,6,10,11}$ In this study also higher incidence of the fistulae was seen in preoperative RT cases. But all the pharyngocutaneous fistulas were managed conservatively with mean healing time of 32 days, which is similar to the study done by SS Queresi et al. ${ }^{4}$ 


\section{CONCLUSION}

Laryngectomy is a procedure which is associated with many complications in the initial days whose incidence has come down with the growing expertise among otorhinolaryngologists. Even then, we have encountered some complications in the postoperative period and w ere successful in managing many of them conservatively. None the less, many more prospective studies and medical audit of the cases should be done to identify the incidence and reasons for the complications to improve the outcome of the surgery which helps in reducing the mortality and morbidity associated with the procedure. We tried to identify retrospectively, the probable causes for their occurrence that it will be useful for proper management of the patients.

\section{ACKNOWLEDGMENT}

W e thank Dr A kurati L enin for hel ping in preparing, drafting and editing the manuscript.

\section{REFERENCES}

1. Seth R. Schwartz, B evan Y ueh, Charles M aynard, Jennifer Daley, W illiam Henderson, Shukri F K huri. Predictors of wound complications after laryngectomy: A study of over 2000 patients. Otolaryngology-Head and Neck Surgery 2004 July;131(1): 61-68.

2. A rriaga MA, K anel KT, Johnson JT, M yers EN. M edical complications in total laryngectomy: Incidence and risk factors. Ann Otol R hinol Laryngol 1990 Aug;99(8):611-15.

3. Ganly I, Patel S, M atsuo J, Singh B, K raus D, B oyle J, et al. Postoperative complications of salvage total laryngectomy. Cancer 2005 M ay 15;103(10):2073-81.

4. Qureshi SS, Chaturvedi P, Pai PS, Chaukar DA, Deshpande MS, Pathak KA, D' cruz AK. D epartment of Surgery, H ead and Neck Surgical Service, Tata M emorial H ospital, M umbai, India. A prospective study of pharyngocutaneous fistulas following total laryngectomy. J Can Res Ther 2005 J an-M ar;1(1):51-56.
5. Sobin LH, Wittekind Ch. TNM classication of malignant tumours (6th ed). N ew Y ork: W iley-Liss 2002;36-42.

6. Wolf G, Hong K, Fisher S. Induction chemotherapy plus radiation compared with surgery plus radiation in patients with advanced laryngeal cancer: The Department of V eterans A ffairs Laryngeal Cancer Study Group. N Engl J Med 1991;324: 1685-90.

7. Hier M , B lack MJ , L afond G. Pharyngocutaneous fistulas after total laryngectomy: Incidence, etiology and outcome analysis. J Otolaryngol 1993;22:164-66.

8. Papazoglou G, Doundoulakis G, Terzakis G, Dokianakis G. Pharyngocutaneous fistula after total laryngectomy: Incidence, cause and treatment. Ann Otol Rhinol Laryngol 1994;103: 801-05.

9. V irtaniemi JA, K umpulainen EJ , Hirvikoski PP, J ohansson RT, Kosma VM. The incidence and etiology of post laryngectomy pharyngocutaneous fistulae. Head Neck 2001;23:29-33.

10. Schuller DE, M etch B, Stein DW, M attox D, M cCracken JD. Preoperative chemotherapy in advanced head and neck cancer: Final report of the South-W est Oncology Group. L aryngoscope 1988;98:1205-11.

11. Corey JP, Caldarelli DD, Hutchinson JC Jr, Holinger LD, Taylor 4th SG, Showel JL, et al. Surgical complications in patients with head and neck cancer receiving chemotherapy. A rch Otolaryngol Head Neck Surg 1986;112:437-39.

\section{ABOUT THE AUTHORS}

\section{Sudarshan L Reddy (Corresponding Author)}

A ssociate Professor, Department of ENT, Siddartha M edical College Government ENT Hospital, K oti, Hyderabad, A ndhra Pradesh, India e-mail: drlsudarshanreddy9@gmail.com

\section{Sridhar D Reddy}

A ssociate Professor, Department of ENT, Siddartha M edical College Vijayawada, A ndhra Pradesh, India

\section{AVVSL Prasad}

Postgraduate, Department of ENT, Osmania Medical College/ Government ENT Hospital, Hyderabad, Andhra Pradesh, India 